\title{
A GESTÃO DEMOCRÁTICA E O PROJETO POLÍTICO PEDAGÓGICO NA CONCEPÇÃO DO PROFESSOR: UM ESTUDO DE CASO
}

http://dx.doi.org/10.5902/2176217110877

\author{
Josiane Folletto Bianchin \\ Universidade Federal de Santa Maria, Brasil. \\ Marta Roseli de Azeredo Barichello \\ Universidade Federal de Santa Maria, Brasil.
}

\begin{abstract}
Resumo
Este trabalho teve por objetivo geral investigar como os docentes percebem o seu papel de gestores e como objetivos específicos compreender como ocorre a gestão democrática participativa na escola, analisar o comportamento dos professores em frente à gestão escolar, investigar a ação e contribuição dos docentes na elaboração e desenvolvimento do projeto político-pedagógico como um espaço de gestão democrática e observar a relação do projeto político-pedagógico da escola com a sua realidade. Esta investigação se baseou em questionários estruturados com perguntas abertas, aplicadas apenas aos professores do noturno do ensino médio, direção, vice-direção e coordenação pedagógica de uma escola estadual de Santa Maria, RS. Ainda que muito seja discutido sobre gestão democrática pode-se perceber que a participação dos professores, que foi o objeto de pesquisa, ainda é limitada na escola. Existem algumas formas de participação que são passivas, destacando a colaboração em festas, o ouvir e aprovar as sugestões da direção, ou até mesmo ouvir e discutir assuntos, mas não de se chegar a nenhum consenso com os demais membros escolares. Ressalta-se que esta pesquisa é, apenas, uma amostra da realidade de uma escola em um determinado período de tempo.

Palavras-chave: gestão democrática, projeto político pedagógico, professor gestor.
\end{abstract}

\section{A DEMOCRATIC POLITICAL PROJECT MANAGEMENT AND INSTRUCTIONAL DESIGN IN TEACHER: A CASE STUDY}

\begin{abstract}
This work had as general objective research into the way in which the teachers saw their role as managers and as specific objectives understand how the democratic participatory management, analyze the behavior of teachers in front of the school management, investigate the action and contribution of the teachers in the elaboration and development of political-pedagogical project as a democratic management space and observe the relationship political-pedagogical project school with its reality. This research is provided through a qualitative study based on structured questionnaires with questions Open applied only to teachers of high school night, direction, vice direction and pedagogical coordination of a state school. Even though much is discussed about democratic management can realize that the participation of the teachers who was the object of


research, is still very limited at school, there are some forms of participation that are passive, highlighting the collaboration at parties, hear and approve the suggestion of direction, or even listen to and discuss issues, but did not reach any consensus with the other members school, pointing out that this research was just a sample of the reality of school in a given period of time.

Key-words: democratic management, political pedagogical project, teacher manager. 


\section{Introdução}

evido à observações acerca do comportamento dos docentes em relação ao desenvolvimento do papel de gestores dentro do ambiente escolar, pensouse em um estudo a respeito desse envolvimento, interesse e comprometimento dos docentes, sobretudo no que se refere ao âmbito da gestão participativa na escola.

Esse trabalho é resultado de uma pesquisa desenvolvida entre maio e dezembro de 2012. A pesquisa teve como objetivo geral investigar como os docentes se veem enquanto gestores de suas escolas e como objetivos específicos: compreender como ocorre a gestão democrática participativa; analisar o comportamento dos professores frente à gestão escolar; investigar a ação e contribuição dos docentes na elaboração e desenvolvimento do projeto político pedagógico como um espaço de gestão democrática; e, observar a relação do projeto político pedagógico da escola com a sua realidade.

Vale ressaltar que todos os setores da escola devem atuar no compromisso de participarem de forma ativa, promovendo a elaboração coletiva e integradora de questões que envolvam o desenvolvimento de ações para uma escola democrática.

Sendo assim, a gestão é entendida como um componente que colabora para a democratização do acesso ao ensino público, não se reduzindo apenas à sala de aula, mas à própria estrutura da escola. Portanto, a gestão, em última análise, pode criar uma noção mais aprofundada de que a educação é responsabilidade de todos, cabendo à comunidade, dentro de suas possibilidades e respeitando seus limites, contribuir para que se processe no ensino público a transformação que todos anseiam.

É possível perceber que, em meio às transformações e inovações que ocorrem na sociedade e na área da educação, surge um novo perfil de professor, que pode ser chamado de professor gestor. O professor gestor é aquele que vê além de seu próprio mundo, que consegue vislumbrar possibilidades de ação onde já não se podia mais esperar nada (Santos; Hartmann, 2009).

Compreender a forma com que os docentes exercem o papel de gestores em suas práticas pedagógicas e as concepções que estes sujeitos têm sobre gestão são pontos importantes para essa pesquisa.

\section{Gestão democrática e participativa na educação básica}

Partindo do conceito de gestão democrática como uma prática participativa e de tomada de decisão, é possível relacioná-lo com a atividade de impulsionar uma organização a atingir seus objetivos, cumprir sua função, desempenhar seu papel (Ferreira, 2008).

A gestão democrática da escola pública, entendida como a participação da comunidade, a partir da autonomia e da descentralização administrativa, ganhou ênfase nas políticas educacionais no Brasil, a partir da década de 1990, especialmente com a Lei de Diretrizes e Bases da Educação Nacional, lei n. 9.394/96.

Propõe-se, como principais instrumentos de gestão escolar democrática, a criação dos conselhos e grêmios estudantis, a elaboração do projeto político pedagógico no âmbito interno, a escolha direta de diretores, dentre outros (Carvalho et al, 2008).

A LDB, em seus artigos 14 e 15, apresentam as seguintes determinações: 
Art. 14 - Os sistemas de ensino definirão as normas da gestão democrática do ensino público na educação básica, de acordo com as suas peculiaridades e conforme os seguintes princípios: I. participação dos profissionais da educação na elaboração do projeto pedagógico da escola; II. participação das comunidade escolar e local em conselhos escolares ou equivalentes. Art. 15 - Os sistemas de ensino assegurarão às unidades escolares públicas de educação básica que os integram progressivos graus de autonomia pedagógica e administrativa e de gestão financeira, observadas as normas de direito financeiro público. (Brasil, 1996)

Os artigos da LDB dispõem que a "gestão democrática do ensino público na educação básica, oferece certa autonomia às unidades federadas para definirem em sintonia com suas especificidades formas de operacionalização da gestão, com a participação dos profissionais da educação envolvidos e de toda a comunidade escolar" (Vieira, 2005). Dessa forma, cabe aos membros das instituições de ensino fazerem valer os seus papéis de gestores no âmbito escolar, com responsabilidade e comprometimento.

Coutinho (2000, p. 20) afirma que a democracia é o "regime que assegura a igualdade, a participação coletiva de todos na apropriação dos bens coletivamente criados". Nessa perspectiva, a democracia implica não apenas em igualdade política, mas também em igualdade de condições de vida para todos, Pode-se dizer que pensar a democratização da gestão educacional implica compreender a cultura escolar e seus processos.

A gestão participativa tem como ponto de partida a participação e a autonomia da comunidade escolar nos assuntos relacionados à sua instituição de ensino. Nessa forma de gestão a participação faz com que os sujeitos envolvam-se de forma direta com a escola na formulação de seus objetivos, metas e atividades pedagógicas. A participação de todos nos diferentes níveis de decisão e nas sucessivas fases de atividades é essencial para assegurar o eficiente desempenho da organização (Marques, 1987).

Lück (2004), ao destacar a importância do trabalho participativo no processo educacional, acresce que esta participação dá às pessoas a oportunidade de controlar o próprio trabalho, além de sentirem-se autoras e responsáveis pelos seus resultados, construindo, portanto, sua autonomia. Ao mesmo tempo sentem-se parte da realidade e não apenas um simples instrumento para realizar objetivos institucionais. Assim, o envolvimento dos que fazem parte do processo educacional no estabelecimento de objetivos e na solução de problemas, proporcionando resultados mais satisfatórios, é de grande importância para a gestão escolar participativa.

Para que se tenha uma educação democrática é preciso uma participação contínua, consciente e clara de toda comunidade escolar nas questões que envolvam não somente a aprendizagem dos alunos, mas as demais questões da escola. Cabe aos sujeitos envolvidos no ambiente escolar participarem de um trabalho coletivo.

\section{Papel do professor enquanto gestor da escola}

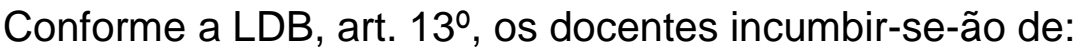

I - participar da elaboração da proposta pedagógica do estabelecimento de ensino; II - elaborar e cumprir plano de trabalho, segundo a proposta pedagógica do estabelecimento de ensino; III - zelar pela aprendizagem 
dos alunos; IV - estabelecer estratégias de recuperação para os alunos de menor rendimento; V - ministrar os dias letivos e horas-aula estabelecidos, além de participar integralmente dos períodos dedicados ao planejamento, à avaliação e ao desenvolvimento profissional; VI - colaborar com as atividades de articulação da escola com as famílias e a comunidade.

Conforme previsto na LDB, os professores são encarregados de atuar nas questões que envolvam a aprendizagem dos alunos, mas também nos assuntos pertinentes ao desenvolvimento das propostas para promover essa aprendizagem, atuando em conjunto com a direção e a comunidade local. Os professores são estimulados a participar não apenas das atividades de sala de aula, mas também da organização e gestão do trabalho escolar (Stedile, 2008).

$\mathrm{Na}$ sala de aula o professor dá continuidade ao que foi definido coletivamente, realizando um trabalho que requer, tanto solidariedade em compartilhar poder e responsabilidades, quanto capacidade de decisão. No entanto, para desempenhar essas funções, seja na sala de aula, seja no âmbito mais amplo da instituição escolar, da organização e gestão do trabalho escolar, o professor necessita ter conhecimentos sobre o aspecto da gestão na educação (Ferreira, 2008).

Com isso, os professores têm de aprenderem novos saberes relacionados à gestão democrática e competências, assim como um modo de agir coletivo e participativo em favor da formação de uma gestão democrática, a partir da participação na tomada de decisões e de valores para a melhoria da escola.

\section{Projeto político pedagógico como elemento articulador de gestão democrática}

A LDB estabelece uma prescrição legal de confiar à escola a responsabilidade de elaborar, executar e avaliar seu projeto pedagógico. Em seu artigo 12, inciso I, prevê que os estabelecimentos de ensino, respeitadas as normas comuns e as do seu sistema de ensino, terão a incumbência de elaborar e executar sua proposta pedagógica. Nessa perspectiva, a escola deve assumir como uma de suas tarefas pensar sobre a sua intenção educativa. O projeto político pedagógico define a identidade da escola e indica caminhos para que se possa ser garantida aos alunos uma educação de qualidade. Este documento, ao se constituir por meio de um processo participativo de decisões, "preocupa-se em instaurar uma forma de organização do trabalho pedagógico que desvele os conflitos e as contradições, buscando eliminar as relações competitivas e autoritárias" (Veiga, 2004, p. 38).

Oliveira (2006) esclarece que a partir do conceito de gestão como administração e organização, pode-se dizer que gestão democrática e projeto político pedagógico são temas intimamente entrelaçados e complexos. Dessa forma, não é possível construir um projeto político pedagógico coletivo sem a efetivação de uma gestão democrática, ao contrário, é pela gestão democrática que se constrói um projeto participativo. Assim, todo planejamento da escola tem que ser subsidiado pela realidade escolar. Pelo projeto político pedagógico se define, então, o modelo de cidadão que se quer para os alunos e professores

Pimenta (1991, p.79) afirma que o projeto político pedagógico 
resulta da construção coletiva dos atores da educação escolar. Ele é a tradução que a escola faz de suas finalidades, a partir das necessidades que lhe estão colocadas, com o pessoal - professores/alunos/equipe pedagógica/pais - e com os recursos de que dispõe.

Para a sua organização deve-se ter o comprometimento de toda equipe escolar, envolvendo as ideias e propostas sugeridas, levando sempre em consideração a tendência pedagógica que a escola considere importante, pois é neste documento que devem estar os princípios e diretrizes para o funcionamento eficaz das atividades a serem desempenhadas.

Verifica-se, assim, que a elaboração do projeto político pedagógico deve contar com o envolvimento de toda a comunidade escolar, promovendo uma efetiva gestão democrática, destacando a autonomia e a participação de todos os envolvidos no âmbito escolar em busca de promover o ensino-aprendizagem de seus alunos.

\section{Metodologia de pesquisa}

Este estudo buscou investigar de que maneira a escola exerce seu papel de gestão democrática e se de fato os professores participam desta gestão. Assim, a presente pesquisa analisa como estes profissionais se veem no papel de gestores em seu ambiente escolar. Para tanto, as entrevistas com os docentes, direção, vice-direção e coordenação pedagógica, além do acompanhamento do cotidiano desses profissionais, é fundamental para a compreensão de como acontece a implementação da gestão democrática na escola.

Esta investigação se constituiu de um estudo de cunho qualitativo, com base em questionários estruturados com perguntas abertas, aplicadas aos professores do período noturno, direção, vice-direção e coordenação pedagógica, com diferentes questões para os docentes, tendo sua interpretação seguida pela análise textual.

Por questionário "entende-se um conjunto de questões que são respondidas por escrito pelo pesquisado" (Gil, 2002, p. 114). Assim, a busca pelos dados começou com uma conversa informal com a direção da escola, para que a partir disso fosse possível conhecer a estrutura da instituição. Após, foi solicitado o projeto político pedagógico da escola para compreender o seu funcionamento.

Os colaboradores dessa investigação foram sete professores que atuam em uma escola de Santa Maria no turno da noite e em diferentes séries do ensino médio que, após terem sido convidados, demonstraram interesse em participar da pesquisa em questão. Participaram, também, a diretora, vice-diretora e coordenadora do turno da noite.

Após a permissão da direção da escola, foi marcada uma data para que fossem levados os questionários para a direção, vice-direção e coordenação pedagógica.

\section{Resultados e apontamentos finais}

Pelo fato dessa pesquisa considerar apenas um período da realidade da escola em questão e somente no turno da noite, muitas questões vivenciadas no estudo podem não refletir a realidade escolar tal como se encontra nos dias de hoje.

Ainda que muito seja discutido sobre gestão democrática, pode-se perceber que a participação dos professores, elemento que foi o objeto dessa pesquisa, ainda é muito 
limitada na escola. Existem algumas formas de participação que são passivas, destacando a colaboração em festas, o ouvir e aprovar as sugestões da direção, ou até mesmo ouvir e discutir assuntos, mas não se chega a nenhum consenso com os demais membros escolares.

Estas formas de participação passivas ou induzidas não proporcionam, aos integrantes do ambiente escolar, de fato, a sua atuação de forma consciente para construir ou modificar a realidade na qual estão inseridos, de modo que não atuam como sujeitos ativos na tomada de decisões coletivas e não se envolvem nos assuntos pertinentes à escola e aos processos de ensino e aprendizagem.

A participação efetiva tende a contribuir para a melhoria da escola, da qualidade de ensino e da resolução de questões que envolvam todo o contexto escolar, caminhando para uma instituição melhor para todos.

Faz-se necessário buscar o envolvimento e o comprometimento de todos os envolvidos sejam, alunos, pais, funcionários, equipe diretiva e professores, nas questões relacionadas à escola, possibilitando uma gestão democrática, com o planejamento participativo do contexto escolar.

Dessa forma, não deve ficar somente a critério da equipe diretiva fazer a disseminação da gestão democrática na escola, os professores tem de se sentirem gestores e se incorporarem neste tipo de gestão. Ademais, é preciso a articulação de todos na construção de saberes imprescindíveis a convivência de forma participativa. Somente assim acredita-se que as ações coletivas tornam os processos dentro da escola mais efetivos, desde as questões administrativas até os processos de ensino e aprendizagem.

O projeto político pedagógico, por ser o documento que expressa a gestão democrática da escola, a participação dos docentes na sua elaboração, desenvolvimento e aplicação, servindo de base para que essa gestão de fato ocorra, foi o elemento principal utilizado na pesquisa.

Pela análise desse documento pode-se perceber que, em alguns pontos, ele não condiz com a realidade escolar e precisa ser revisto, tal como relatado por quatro professores, já que muito do que foi definido neste projeto, já não faz mais parte do contexto da escola. Um destes docentes citou que, principalmente no que se refere ao perfil dos alunos do noturno, que antes abrangia estudantes adultos e trabalhadores, agora é constituído por uma maioria de alunos mais jovens.

Ademais, é possível observar que há a participação dos docentes na elaboração deste projeto, porém muitos deles não procuram executá-lo, sendo este um indicativo de que os docentes não se percebem enquanto gestores em sua prática. Dessa forma, a gestão democrática não ocorre em todos os seus sentidos, pois os docentes deveriam seguir o projeto pedagógico em sua totalidade, em todos os momentos de sua atuação na escola, para que assim se alcançassem os objetivos planejados neste documento.

Por fim, é imprescindível destacar que os professores precisam ter mais consciência de que sua participação no processo da gestão democrática, pois a sua ação não deve se restringir apenas à sala de aula, mas sim a todo âmbito escolar. Com isso, gestão escolar tem que ocorrer ativamente nas escolas embora essa questão ainda não esteja sendo bem clara e entendida por todos. 


\section{Referências}

CARVALHO, Elma Julia Gonçalves et al. Gestão escolar. Maringá: UEM, 2008.

COUTINHO, Carlos Nelson. Cultura e sociedade no Brasil. Rio de Janeiro: DP\&A, 2000.

FERREIRA, Naura Syria Carapeto (org.). Gestão democrática da educação: atuais tendências, novos desafios. São Paulo: Cortez, 2008.

GIL, Antonio Carlos. Como elaborar projetos de pesquisa. São Paulo: Atlas, 2002.

Lei de Diretrizes e Bases da Educação Nacional. Brasília: Imprensa Oficial, 1996.

LUCK, Heloísa. A dimensão participativa da gestão escolar. Gestão em rede, v. 57, 2004, p. 1-6.

MARQUES, Juracy Cunegatto. Administração participativa. Porto Alegre: Sagra, 1987.

OLIVEIRA, Silvana Barbosa. Gestão democrática e a construção do projeto político pedagógico: um desafio para intervenção. Curitiba: Seed, 2006.

PIMENTA, Selma Garrido. O pedagogo na escola pública. São Paulo: Loyola, 1991.

STEDILE, Maria Inez; CARVALHO, Elma Júlia Gonçalves. O professor como gestor da sala de aula. Maringá: UEM, 2008.

VEIGA, IIma Passos Alencastro. Educação básica e educação superior: projeto políticopedagógico. Campinas: Papirus, 2004.

VIEIRA, Sofia Lerche. Educação e gestão: extraindo significados da base legal. In. SEDUC. Novos paradigmas de gestão escolar. Fortaleza: Seduc, 2005, p. 7-20.

Josiane Folletto Bianchin é estudante do curso de Pós-Graduação em Gestão Educacional da Universidade Federal de Santa Maria.

Endereço: Rua Visconde de Pelotas, 1700/401 - 97015140 - Santa Maria RS - Brasil.

E-mail: josiane1515@hotmail.com.

Marta Roseli de Azeredo Barichello é professora no curso de curso de PósGraduação em Gestão Educacional da Universidade Federal de Santa Maria.

Endereço: Avenida Roraima, 1000 - 97105-900 - Santa Maria - RS - Brasil.

E-mail: martaquartacolonia@gmail.com.

Recebido em 2 de setembro de 2013.

Aceito em 4 de dezembro de 2013. 